\title{
A POLÍTICA DE DESENVOLVIMENTO URBANO: OS PROGRAMAS DE REGULARIZAÇÃO FUNDIÁRIA EM APP URBANAS E O DESAFIO DE IMPLEMENTAÇÃO DO DIREITO À CIDADE
}

Jeane Aparecida Rombi de Godoy Rosin'1

Márcio Antônio Teixeira²

RESUMO: O presente artigo tem por objetivo desenvolver uma reflexão a respeito da complexidade que envolve a efetivação do direito à cidade - direito fundamental - a partir de sua compreensão enquanto um feixe de direitos assegurados constitucionalmente. Com este propósito, se define como recorte analítico os Programas de Regularização Fundiária no contexto da Política Nacional de Desenvolvimento Urbano, enquanto resposta estatal às gritantes demandas decorrentes dos processos de informalidade, especificamente àqueles verificados nas APPs urbanas, tendo em vista as conflituosas discussões que permeiam a complexa questão em torno do direito à moradia e ao meio ambiente, e sua condição imperativa para o alcance pleno do direito à cidade. Desse modo, a discussão estrutura-se, partindo de uma abordagem genérica, com o intuito de compreender o descompasso existente entre a formulação da política urbana e habitacional e as diversidades geográficas, sócio-culturais das áreas urbanas de cada localidade, especificamente dos processos de produção dos assentamentos precários em APP (Área de Preservação Permanente) Urbanas localizadas em regiões metropolitanas brasileiras, após a edição do Estatuto da Cidade. Com este propósito, pretende desenvolver uma breve avaliação da Política Nacional de Desenvolvimento Urbano por meio dos Programas de Regularização 
Fundiária Sustentável, considerando as inter-relações entre as dimensões sociais, econômicas e ambientais. Sob esta ótica, o estudo será desenvolvido, a partir de uma discussão relacionada aos conflitos jurídicos oriundos da complexa interface do Direito Urbanístico e Ambiental, no tocante a viabilização de Projetos de Intervenção Urbana de Assentamentos Precários, especificamente em APP Urbanas. Pretende ainda, realizar uma reflexão sobre a efetividade do Estatuto da Cidade na promoção de uma cidade sustentável, considerando a implementação dos instrumentos jurídicos e urbanísticos, voltados a garantia do Direito à Cidade por meio dos Programas de Regularização Fundiária Sustentável em Assentamentos Informais. A metodologia adotada será a qualitativa, e basear-se-á em um roteiro estruturado a partir da temática proposta: a de pesquisa bibliográfica e documental para exploração do tema proposto. Com os resultados desta reflexão, pretende-se verificar a efetividade da Política Nacional de Desenvolvimento Urbano - para a formatação de programas (Regularização Fundiária Sustentável) aptos a responder de modo eficaz aos desafios e dilemas presentes em boa parte das cidades brasileiras.

PALAVRAS-CHAVE: Áreas de Preservação Permanente. Assentamentos Precários. Regularização Fundiária. Política de Desenvolvimento Urbano. Direto à Cidade.

\section{INTRODUÇÃO}

O III Fórum Urbano Mundial da UN-HABITAT, assim como seu Relatório sobre a Situação Mundial das Cidades 2006/2007, mobilizou com sucesso o interesse global para a deterioração das condições sociais e ambientais de localidades urbanas. $O$ processo de globalização também atraiu a atenção mundial, tanto para o potencial produtivo das cidades, como para o seu custo humano (UNFPA, 2007, p. 02).

Segundo Robert Kunzig da National Geographic (2011), a população do mundo continuará a aumentar nos próximos anos, o que implica no consumo de mais recursos naturais, bem como a na intensificação dos quadros de miséria no contexto mundial, notadamente em áreas urbanizadas. Neste contexto, a ONU - Organização das Nações 
Unidas informa que a população global poderá ser estabilizada no ano de 2045 com um valor médio de 9 bilhões de habitantes.

\begin{abstract}
Embora seu ritmo esteja diminuindo, essa explosão demográfica está longe de terminar. As pessoas passaram a viver mais tempo e há tantas mulheres ao redor do mundo em idade de procriar - 1,8 bilhões - que a população global ainda vai continuar crescendo pelo menos durante algumas décadas, mesmo que cada mulher tenha menos filhos que na geração anterior. Até 2050, o total de seres humanos no planeta pode chegar a 10,5 bilhões ou então se estabilizar por volta dos 8 bilhões - a diferença é de cerca de um filho para cada mulher. Os demógrafos da ONU consideram mais provável a estimativa média: eles estão projetando uma população mundial de 9 bilhões antes de 2050 - em 2045. [...] Com a população mundial a aumentar ao ritmo de cerca de 80 milhões de pessoas por ano, é difícil não ficar alarmado. Em toda a terra, os lençóis freáticos estão cedendo, os solos ficando cada vez mais erodidos, as geleiras derretendo e os estoques de pescado prestes a ser esgotado. Quase 1 bilhão de pessoas passam fome todo o dia. Daqui a algumas décadas, haverá mais 2 bilhões de bocas a ser alimentadas, a maioria em países pobres. E bilhões de outras pessoas lutarão para sair da miséria. Se seguirem pelo caminho percorrido pelas nações desenvolvidas desmatando florestas, queimando carvão e petróleo, usando fertilizantes e pesticidas com abundância -, vai ser enorme o impacto sobre os recursos naturais do planeta. Como podemos conciliar tudo isso? ${ }^{1}$
\end{abstract}

Em que pese as previsões de uma super explosão demográfica não se confirme, frustrando a visão malthusiana ${ }^{2}$ da problemática em questão, há um aspecto preocupante que deve ser abordado. Trata-se do crescimento espacial desigual, pois de cada dez novos nascimentos, nove ocorrerão em países periféricos.

Além disso, a curva de crescimento da população das cidades com mais de 100 mil habitantes tem sido muito mais acentuada do que a população total. $\mathrm{O}$ aumento da concentração urbana pode suplantar a capacidade de suporte dos ecossistemas urbanos ${ }^{3}$ para a manutenção equilibrada da vida.

\footnotetext{
1 Artigo Online - População mundial: já somos 7 bilhões. Edição 130, publicado em 01.01.2011. Disponível em < http://viajeaqui.abril.com.br/national-geographic/edicao-130/populacao-mundial-7-bilhoes613876.shtml > Acesso em 07.05.2011

${ }^{2}$ Segundo Malthus (1983, p. 282) expôs: "Estão, adotando meus postulados como certos, afirmo que o poder de crescimento da população é indefinidamente maior do que o poder que tem a terra de produzir meios de subsistência para o homem".

${ }^{3}$ Segundo Dias (1997, p. 20), ecossistemas urbanos são "sistemas abertos altamente dependentes de outros ecossistemas do seu entorno, com os quais interage através de fluxos e trocas. Do ponto de vista biológico os ecossistemas urbanos exibem uma baixíssima produtividade, logo, são altamente dependentes de outros sistemas".
} 
A conseqüência desse tipo de crescimento demográfico, aliada às restrições econômicas ocorridas nestas últimas décadas, tem se revelado como tendência peculiar da anárquica urbanização brasileira, a qual contribuiu para a conseqüente queda da qualidade de vida urbana. Este processo está associado à degradação ambiental, que afeta mais fortemente os extratos sociais de menor renda, ou seja, as populações mais carentes estão assentadas em áreas desprovidas de infraestrutura e também estão, freqüentemente, em espaços urbanos de alto risco sujeito a enchentes, deslizamentos e processos erosivos.

$\mathrm{Na}$ realidade, as cidades brasileiras são frutos de processos muito equivocados de planejamento e gestão onde as consequências, podem ser avaliadas a partir da diversidade de problemas e demandas existente em toda a rede urbana do país ${ }^{4}$.

Neste contexto, Lucas (2009) salienta que,

\begin{abstract}
Diversos fatores, principalmente 0 processo de acumulação de capital e concentração de riquezas típicas do capitalismo periférico, contribuíram para o quadro de segregação espacial existente nos países em desenvolvimento. A propriedade imobiliária, neste contexto, aparece como mais uma fonte de concentração de riqueza e poder político, restrita a grupos privilegiados. O que se observa hoje é um quadro de exclusão generalizado para a maioria dos moradores de centros urbanos: das decisões políticas, do acesso ao emprego formal, do acesso à moradia digna e infra-estrutura urbana, do direito a cidade $\mathrm{e}$, principalmente, do direito a cidadania. A ordem jurídica em vigor, privilegiando o direito de propriedade individual e utilizando-se de leis elitistas, reforça o quadro de segregação, protegendo o patrimônio imobiliário de uma camada da população enquanto impele a grande massa de trabalhadores para a ilegalidade (LUCAS, 2009, p. 56).
\end{abstract}

A partir desse contexto, um quadro extremo de desigualdade na distribuição de riquezas foi se intensificando na maioria das cidades brasileiras, onde uma parcela significativa da população foi forçada a viver em situação de risco social e ambiental imposta em boa parte, pela condição socioeconômica.

Para vários autores, entre eles Flávio Villaça (1998), a análise do espaço urbano, sobretudo nos grandes centros, identifica como aspecto marcante a discrepância dos usos

\footnotetext{
${ }^{4} \mathrm{~A}$ rede urbana é formada pelo sistema de cidades, interligadas umas às outras por meio dos sistemas de transportes e de comunicações, pelos quais fluem pessoas, mercadorias, informações, entre outros. Para Fresca (2004, p.38), a rede urbana com seu conjunto de cidades, de infraestruturas de transporte, comunicação, informação, dentre outros, "envolve inúmeras relações de integração interna e externa, e ao mesmo tempo manifesta novos padrões de desigualdades vinculados aos processos sociais." (FERREIRA, 2008, p. 540)
} 
residenciais conforme o perfil socioeconômico da população residente, o que comumente é denominado de segregação socioespacial, produzida a partir de uma dinâmica desconexa, que se mostra na guetificação da elite - morando em condomínios residenciais fechados com confortos que transcendem os limites urbanísticos máximos, e na concentração informal de população de menor poder aquisitivo, vivendo em áreas inadequadas e muitas vezes, desprovidas do mínimo existencial, totalmente a margem da legislação vigente.

Desse modo, a segregação espacial acaba por se revelar como um dos principais agentes do processo de exclusão social e da degradação ambiental, constituindo-se nos chamados enclaves de pobreza, que inegavelmente são locais de demandas inesgotáveis. Entretanto, há uma outra face a ser considerada nestas áreas, e por sinal de grande importância para o recorte analítico definido nesta reflexão, que são os impactos ambientais oriundos do uso e ocupação desordenada verificados nestas localidades, principalmente em ecossistemas frágeis, como as APPs - Áreas de Preservação Permanente. Mazetto (2000) ensina que esses impactos não se restringem apenas às alterações adversas in pejus do equilíbrio ecológico, mas estão relacionadas à qualidade de vida humana.

Os problemas ambientais não estão restritos aos efeitos das alterações provocadas pelo homem na natureza, que colocam em risco sua própria sobrevivência como espécie, eles também estão relacionados ao próprio espaço construído pelo homem, esse mundo artificial sobre a superfície terrestre, representado especialmente pelas cidades, onde as questões de ordem social e não apenas as de ordem física atuam de forma decisiva na qualidade de vida humana (MAZETTO, 2000, p.21).

Esta questão pode ser melhor compreendida com as análises empreendidas por Mueller (1997) ao tratar da problemática ambiental em áreas urbanas. Segundo este autor, a pobreza e a concentração de população nos grandes centros urbanos brasileiros foram responsáveis pela existência de dois graves problemas ambientais: a degradação do ambiente decorrente do padrão de consumo dos extratos de renda média e alta; e a degradação ocasionada pela ausência de infraestrutura, e a generalizada deficiência de serviços básicos aos segmentos de menor renda.

Certamente, a atual situação de desigualdade, diversidade e instabilidade social em que está inserida boa parte da sociedade brasileira, onde uma parcela significativa da 
população fica alijada do processo urbano, amontoada em imensas periferias, privadas do exercício da cidadania e do usufruto do bem público, é o que motiva a luta pela efetivação do Direito à Cidade.

\section{O PROCESSO DE URBANIZAÇÃO NO BRASIL}

Ao longo das últimas décadas, o intenso processo de urbanização das cidades brasileira foi drasticamente marcado pela descontrolada ocupação informal em áreas de fragilidade ambiental, muitas inseridas em áreas de risco, tais como: as áreas de preservação permanente, áreas de mananciais, áreas de encostas, áreas non-aedificandi, ou seja, áreas tuteladas pelo ordenamento jurídico em razão de seus valores ambientais.

A ocorrência estrondosa dos processos de informalidade urbana, em áreas periféricas, assim como a intensa densificação dos assentamentos informais consolidados, é para alguns autores dentre eles, SMOLKA (2003, p.263), decorrentes não apenas do aumento absoluto e relativo de pobres urbanos, mas, sobretudo da "falta de programas habitacionais, da queda de investimentos públicos em equipamentos urbanos e serviços, e do próprio esvaziamento do planejamento urbano", sem contar que "todos esses são fatores que, em última análise, incidem diretamente na oferta do solo urbanizado". Nesse sentido, é de fundamental importância considerar que, o acesso ao mercado regular de terras está diretamente vinculado ao poder de aquisição ou de compra da população, o que vem esclarecer o motivo pelo qual, milhares de famílias de menor poder aquisitivo, são circunstancialmente obrigadas a ocuparem de modo irregular áreas públicas ou privadas, muitas destas, impróprias à ocupação humana.

Em síntese, os processos de ocupações informais podem ser entendidos como resultados dos ciclos econômicos manifestados drasticamente no processo de produção das cidades, caracterizadas acentuadamente pela concentração de renda, assim como pela omissão do Estado.

A partir deste contexto, os assentamentos informais localizados em áreas ambientalmente vulneráveis, passaram a se constituir num aspecto que vai muito além da delicada problemática urbana, tendo em vista a complexidade das questões de ordem 
jurídica, social, econômica, cultural, e principalmente urbanística, decorrentes da longa e vergonhosa ausência do Estado frente à questão. Todavia, em razão da dimensão e da gravidade com que essas tipologias aparecem nos cenários urbanos, tendo em vista, que parte considerável delas são instaladas em espaços legalmente protegidos, a questão que envolve os processos de regularização fundiária em APP urbanas, tem de modo contundente, não apenas pautado os atuais debates nos mais diversos meios, como também, causado o despertar do Estado para o cumprimento de suas responsabilidades constitucionais relacionadas à efetivação do Direito à Cidade.

Neste sentido, a percepção da questão urbana envolve necessariamente diversos aspectos, que se manifestam em escalas e contextos diferenciados, porém correlacionados, como a exclusão social, a segregação espacial, o desemprego, a violência, a interferência do capital imobiliário nos processos de gestão urbana, e a degradação do meio natural, dentre tantos outros. Assim, torna-se inquestionável, que o quadro de precariedades decorrentes desses aspectos foi produzido ao longo do processo de urbanização do país, o qual foi por muito tempo negligenciado, e que em razão de seus efeitos nefastos, vem ao longo das décadas comprometendo o desenvolvimento nacional, e agora de modo irrefutável, vem exigir do Estado o inadiável cumprimento de suas responsabilidades à luz do princípio da eficiência, que para Jacques Távora Alfonsin (2006, p. 171) se constitui no "princípio constitucional que mais diretamente diz com a responsabilidade do Estado". Nesta abordagem, o referido autor é categórico ao afirmar,

\begin{abstract}
No que concerne ao Estado, é inquestionável o fato de que a sua responsabilidade maior, a respeito do direito de acesso da população à terra, como bem de vida garante casa e comida, está na sua histórica inadimplência em cumprir o princípio da eficiência, previsto no art.37 da CF. Esse princípio não traduz uma obrigação de meio, mas sim resultado, ainda mais em se tratando de função social da terra, pela óbvia relevância desse bem para povo. Basta a leitura, por exemplo, do Estatuto da Terra e do Estatuto da Cidade, sem falar na Constituição Federal, para convir-se que não é por falta de instrumentação jurídica que aquele acesso, no que depende de implementação de políticas públicas previstas para as urgências sociais em causa, ou fica permanentemente prorrogado, ou é mal satisfeito (ALFONSIN, 2006, p.171).
\end{abstract}

Frente a esse contexto, emerge a necessidade imperiosa de uma nova ordem constitucional, apta a restabelecer o Estado Democrático de Direito no Brasil, com o intuito 
de assegurar não somente a igualdade de todos frente à lei, mas sobretudo com uma nova concepção de Estado, a partir da incorporação dos Direitos Fundamentais.

É papel do Estado, como entidade reguladora e mediadora das relações e conflitos oriundos entre os interesses particulares e os interesses comuns (de ordem pública), encontrar mecanismos para mitigar as desigualdades socioeconômicas da sociedade brasileira. Desse modo, os autores do texto constitucional por meio de dois artigos (art.182 e art.183) definiram os primeiros tópicos legais para a incorporação do inédito capítulo da política urbana, concebida com a missão essencial de promover o pleno desenvolvimento das funções sociais da Cidade e de garantir o bem estar de seus habitantes.

Nesse sentido, o artigo 182 da Carta Pátria, coloca como preceito da política urbana, a realização do pleno desenvolvimento das funções sociais da cidade que, segundo Fiorillo (2003, p. 257) deve ser assegurada de modo a promover a dignidade da pessoa humana à luz dos princípios constitucionais, ou seja,

[...] é cumprida quando proporciona a seus habitantes o direito à vida, à segurança, à igualdade, à propriedade e à liberdade (CF, art. 50, caput), bem como quanto garante a todos um piso vital mínimo, compreendido pelos direitos sociais à educação, à saúde, ao lazer, ao trabalho, à previdência social, à maternidade, à infância, à assistência aos desempregados, entre outros encontrados no art. $6^{\circ}$ (FIORILLO, 2003, p. 257).

Para a garantia de efetividade aos princípios e instrumentos contemplados no texto constitucional - relativos à questao urbana, torna-se essencial a regulamentação de legislação específica em âmbito federal. O que mais tarde se consolida com a edição do Estatuto das Cidades, viabilizando o direito à moradia digna, elencando no rol dos novos instrumentos jurídicos e urbanísticos - a regularizaçao fundiária como estratégia fundamental de intervençao em áreas de assentamentos humanos informais, como uma das principais diretrizes da Política Urbana. Em meio a um cenário constituído por obstáculos de toda ordem, onde as possibilidades de uma ação efetiva do planejamento sobre a informalidade urbana era ainda visto com muito descrédito, coube ao Estado reconhecer e assumir todo o contexto resultante especificamente do déficit habitacional e buscar os meios necessários para o enfrentamento desta gigantesca demanda, tentando reorganizar a máquina governamental na tentativa de assegurar que esses assentametos 
tivessem a possibilidade de conquistarem sua inclusão em todas as dimensões da cidade formal. De certo modo, esta estratégia se articula com o propósito de viabilizar ainda que, seja em dimensão abstrata do ordenamento jurídico e dos procedimentos cartoriais, as mesmas condições institucionais estendidas à cidade "formal". Certamente é a partir das ações de afirmação do direito de moradia, desdobradas no direito de posse ou propriedade de habitações instaladas em assentamentos informais que fundamentam a natureza inovadora da Lei Federal 10.257/2001, propiciando a incorporação de novos atributos na busca de uma nova perspectiva de atuação para o planejamento urbano.

A partir de tais pressupostos, foram delineados um novo aparato de instrumentos e mecanismos para compor a legislação urbanística, possibilitando a formulação de um conjuno de políticas públicas destinadas aos programas de regularização fundiária e urbanização de assentamentos precários. Essa nova postura, não deixa de evidenciar a natureza crítica do planejamento urbano em um contexto de modernização retardatária, pois segundo Carrasco (2011, p.174) "passa a se expressar também através da incorporação, nas políticas públicas e nos projetos urbanísticos, de situações antes consideradas inaceitáveis".

Em que pese, deve-se ressaltar que apesar dos programas de Regularização Fundiária Sustentável, tenham por finalidade primeira a redução das desigualdades sociais, por meio dos diversos instrumentos e mecanismos pautados pelo princípio da dignidade da pessoa humana, visando à efetivação do direito fundamental social à moradia, bem como o Direito à Cidade, é inegável seu caráter curativo, onde a questão da prevenção tem mecanismos muito subjetivos, inconsistentes e frágeis frente à complexidade da questão, esses fatos além de confirmados por diversas pesquisas já realizadas, podem também ser constatados por um simples exercício de observação dos atuais cenários urbanos - locais de intervenções onde tais práticas já foram implementadas, por meio dos intitulados Programas de Regularização Fundiária Sustentável, nas modalidades dos projetos de Urbanização de Áreas Faveladas (Figura 01). 
Figura 01: Bairrinho Vila Carumbe em Realengo, Rio de Janeiro.

ANTES

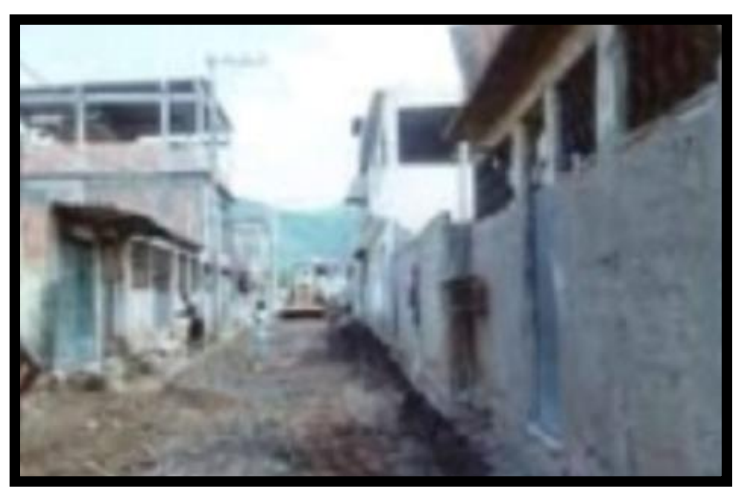

Fonte: Disponível em: < http:// www.vitruvius.com.br > Acesso em 04/04/2011
DEPOIS

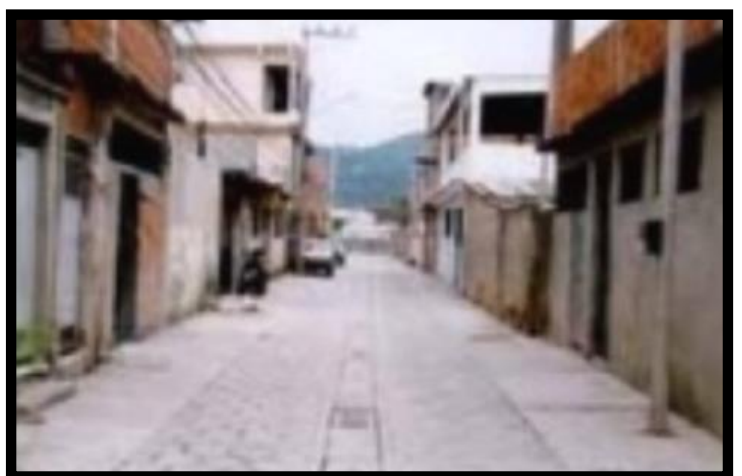
(1)

Desse modo, o contexto apresentado, além de reafirmar a desenfreada crise encontrada em parte significativa das cidades brasileiras, evidencia a premência de adoção de novos paradigmas de planejamento e gestão das cidades, notadamente no que se refere à questão do direito à cidade, enquanto feixe de direitos, os quais deverão ser implementados por meio de políticas públicas capazes de oferecer respostas às demandas por padrões sustentáveis de vida em áreas urbanizadas.

Considerando as recentes edições de normativas urbanísticas e ambientais que orientam a formatação e implementação das atuais políticas governamentais elaboradas para o enfrentamento dos processos de informalidade, não se pode deixar de considerar que a proposta dos Programas de Regularização Fundiária enquanto programas de política pública de inclusão social ou que tenha a incubência em ser de inclusão, enquanto resposta governamental às volumosas demandas oprimidas por anos, ainda que tardiamente, se constitui num instrumento de extrema importância para a política de desenvolvimento urbano. Porém, as cidades por apresentarem quadros que beiram o caos, entram o novo século clamando por ações de toda ordem.

A partir deste contexto o Governo Federal, com a criação do Ministério das Cidades, sinaliza que há possibilidades de novas perpectivas para o tratamento das questões relacionadas ao desenvolvimento urbano. Com esta preocupação diversas ações 
foram implementadas, dentre as quais se destacam o Conselho Nacional das Cidades, como também a formatação de novas políticas comprometidas em garantir o acesso a todos indistintamente ao tão apregoado direito à cidade.

Certamente, a percepção das causas que conduzem e motivam o processo de crescimento das áreas urbanas é de extrema relevância para a busca de intervenções que tenham como meta a construção de cidades justas, inclusivas, sustentáveis e democráticas. Neste contexto, a discussão a respeito da problemática da efetividade das políticas públicas, gestão urbana e qualidade de vida são essenciais para uma reflexão analítica do paradigma do Direito à Cidade.

\section{A REGULARIZAÇÃO FUNDIÁRIA COMO POSSIBILIDADE DE EFETIVAÇÃO DO DIREITO À CIDADE.}

A questão fundiária das áreas urbanas no Brasil, intensamente assinalada por um padrão austero definido com a edição em 1850 da Lei de Terras, se constituiu no primeiro grande marco na estruturação do arcabouço jurídico moderno da terra no país. Com a aprovação desta lei, houve uma limitação drástica das possibilidades de acesso a terra por meio do trabalho, ou seja, da posse, ao estabelecer como procedimento único de acesso à esse bem - a sua compra, e não mais seu uso. A partir deste contexto, a questão fundiária urbana no país assumiu proporções e complexidades monstruosas. Para Balbim (2010, p.295) essa problemática "resulta de um passivo construído ao longo dos séculos de uma visão patrimonialista ligada à terra, visão essa edificada pelas elites dominantes do país por meio, entre outros, do poder do Estado na definição de normas".

Desse modo, procura-se desenvolver um estudo a partir da contextualização dos cenários urbanos, onde serão apresentados os desafios e dilemas enfrentados na aplicação de políticas de regularização fundiária destinadas à assentamentos informais, como também os principais mecanismos normativos criados no ordenamento jurídico brasileiro, sobretudo a partir da Constituição federal de 1988.

O estudo desse fenômeno tem mostrado ao longo dos anos, que o acelerado processo de urbanização brasileiro se constituiu num dos fatores responsáveis pela 
profunda crise urbana, assinalada por um misto de segregação socioespacial, alto déficit habitacional, degradação ambiental como também o acentuado acesso informal à terra urbana que vem assolando de modo contundente às cidades brasileiras, especificamente as áreas metropolitanas.

A conseqüência desse tipo de crescimento demográfico, aliada às restrições econômicas ocorridas nestas últimas décadas, tem se revelado como tendência peculiar da anárquica urbanização brasileira, a qual contribuiu para a conseqüente queda da qualidade de vida urbana. Este processo está associado à degradação ambiental, que afeta mais fortemente os extratos sociais de menor renda, ou seja, as populações mais carentes estão assentadas em áreas desprovidas de infraestrutura, como também em espaços urbanos de alto risco sujeito a enchentes, deslizamentos e processos erosivos. Tais condições, contribuem de um modo ou de outro, para a ocorrência de desastres naturais afetando diversas cidades brasileiras, sobretudo a população de menor renda. Frente a complexidade envolvida, se faz necessário rever os critérios que orientam os programas de regularização fundiária em áreas de vulnerabilidade ambiental. Estes fatos demonstram que em muitas situações, tem ocorrido certa incoerência ao se conceber os programas de regularização fundiária em áreas faveladas, visto que esses assentamentos, em regra, estão localizados em áreas ambientalmente frágeis.

Certamente, a atual situação de desigualdade, diversidade e instabilidade social em que está inserida boa parte da sociedade brasileira, onde uma parcela significativa da população fica alijada do processo urbano, amontoada em imensas periferias, privada do exercício da cidadania e do usufruto do bem público, é o que motiva a luta pela efetivação do Direito à Cidade.

Diante destes cenários, a legislação brasileira, tem-se preocupado em criar mecanismos voltados para o desafio de alcançar a reversão dos mesmos. Na realidade, o contexto apresentado evidencia, que a questão da regularização está apenas começando e que há um árduo caminho a ser percorrido, tendo em vista o balanço insatisfatório apresentado por esses programas até o momento no país.

A partir desse contexto, a regularização fundiária torna-se uma questão fundamental tanto no desenvolvimento como para a efetivação da política urbana nacional. Foi com esse propósito - com base no Estatuto da Cidade, que se deu a formatação do 
Programa Minha Casa Minha Vida (PMMV) regulamentando por meio da Lei Federal no 11.977/2009 a Regularização Fundiária Sustentável, com a finalidade de assegurar acesso à moradia digna em conformidade com o conceito de habitabilidade, e à cidade formal para os extratos sociais de menor renda - estes foram os pressupostos que pautaram sua edição. Entretanto, a implementação de algumas etapas destes programas, tenham revelado práticas contraditórias e incoerentes com suas bases estruturais.

Porém, não se pode deixar de considerar a relevância da aprovação desses dois novos diplomas jurídicos para o fortalecimento dos desafios referentes ao enfrentamento dos processos de informalidade urbana. Assim, torna-se também importante ressaltar que os programas de Regularização Fundiária, enquanto instrumento fundamental da Política de Desenvolvimento Urbano,constituem-se antes de tudo, ainda que tardiamente, em alternativas criadas pelo Estado, não apenas para a definição de uma ordem urbanística que se deseja inclusiva, mas como condição sine qua non de combate aos processos cíclicos de informalidade urbana. Em síntese, os apontamentos realizados, procuraram evidenciar alguns dos diversos aspectos que envolve a questão urbana no Brasil, ao explicitar que a mesma permaneceu por muito tempo abandonada a própria sorte, proporcionando o aumento vertiginoso de demandas nas mais diversas áreas, que inegavelmente se cristalizam em tipologias disformes e vulneráveis a todo tipo de riscos e vulnerabilidades. Frente aos efeitos decorrentes desse processo, tem-se o despertar do Estado, o qual tem procurado agir por meio de políticas públicas, que até o momento não tem conseguido produzir resultados satisfatórios.

Em face da exposição apresentada, pode-se depreender, que não se trata apenas de prover moradia, é imprescindível que o novo desenho de políticas públicas de desenvolvimento urbano incorpore de modo imperativo a definição de ações visando o alcance do pleno direito à qualidade de vida, não se limitando ou satisfazendo em oferecer de modo vexatório a possibilidade de sobrevivência àqueles que ao longo de décadas sequer conseguiram um local para morar. Assim, é de fundamental importância, que tanto as Políticas Públicas voltadas para a questão urbana sejam integradas a um Projeto de Desenvolvimento da Nação, concebido em essência, com coragem de romper padrões, e força o suficiente para inaugurar um nova era - pautada pelos valores de uma ética urbana - a era de um planejamento alicerçado por mecanismos inovadores, não somente com 
capacidade propositiva mas sobretudo com instrumentos de gestão aptos a realizar a tão sonhada Reforma Urbana.

Diante a tais propósitos, as demandas sociais e ambientais presentes nas cidades brasileiras não podem mais ser toleradas, nem pela ordem urbanística e muito menos pela ordem jurídica, pois os dados apresentados em diversas pesquisas elaboradas por orgãos governamentais e entidades acadêmicas indicam que as famílias de menor ou sem renda são as mais numerosas, desprovidas e desassistidas em suas necessidades mais elementares, o que torna evidente que esses programas deveriam necessariamente procurar responder a essas demandas, ou seja, a dos grupos economicamente desfavorecidos.

Frente a esse contexto, torna-se mister que a formatação das Políticas Públicas em qualquer setor, deva visar primordialmente 0 atendimento das necessidades primeiras do cidadão em situação de vulnerabilidade, e não serem pautadas exclusivamente pelo interesse de grupos hegemônicos, os quais tem dominado ao longo dos anos o arranjo político e econômico do país, causando de modo indireto o comprometimendo da realização de um desenvolvimento em bases justas e democráticas.

Neste sentido, concordamos com Vilani (2006, p.36, negrito nosso) quando o autor afirma que não podemos nos submeter à idéia de "subordinação econômica em relação ao capital hegemônico inerente ao processo histórico do desenvolvimento capitalista brasileiro, aceitando, ao final, para pobre, uma política pobre".

\section{CONSIDERAÇÕES}


Sem a intenção de exaurir as várias nuances compreendidas no processo de regularização fundiária, esta breve reflexão teve a preocupação em apresentar o complexo contexto que envolve os programas destinados a efetivar a regularização fundiária especificamente, aquelas verificadas em APPs urbanas em cidades no Brasil. Desse modo, procurou desenvolver uma breve analise a partir da contextualização dos cenários urbanos, onde foram apresentados os desafios e dilemas enfrentados na aplicação de políticas de regularização destinadas à assentamentos informais, como também os principais mecanismos jurídicos criados no ordenamento jurídico brasileiro, sobretudo a partir da Constituição federal de 1988. Assim, conforme exposição realizada, pode-se depreender que o processo de urbanização das cidades no país, tanto aqueles relativo às cidades de médio e grande porte, intensificou os processos de diferenciação socioespacial. Dessa forma, o estudo desse fenômeno, tem mostrado ao longo dos anos, que o acelerado processo de urbanização brasileiro se constituiu num dos fatores responsáveis pela profunda crise urbana, assinalada por um misto de segregação socioespacial, alto déficit habitacional, degradação ambiental como também o acentuado acesso informal à terra urbana que vem assolando de modo contundente as cidades brasileiras. A conseqüência desse tipo de crescimento demográfico, aliada às restrições econômicas ocorridas nestas últimas décadas, tem se revelado como tendência peculiar da anárquica urbanização brasileira, a qual contribuiu para a conseqüente queda da qualidade de vida urbana. Este processo está associado à degradação ambiental, que afeta mais fortemente os extratos sociais de menor renda, ou seja, as populações mais carentes estão assentadas em áreas desprovidas de infraestrutura e também estão, freqüentemente, em espaços urbanos de alto risco sujeitos a enchentes, deslizamentos e processos erosivos.

Diante destes cenários, a legislação brasileira, tem-se preocupado em criar mecanismos voltados para o desafio de alcançar a reversão dos mesmos. Na realidade, 0 contexto apresentado evidencia, que a questão da regularização está apenas começando e que há um árduo caminho a ser percorrido, tendo em vista o balanço insatisfatório apresentado por esses programas até o momento no país. A partir desse contexto, a regularização fundiária torna-se uma questão fundamental tanto no desenvolvimento como para a efetivação da política urbana nacional. Porém, não se pode deixar de considerar a relevância da aprovação dos novos diplomas jurídicos para o fortalecimento dos desafios 
referentes ao enfrentamento dos processos de informalidade urbana. Assim, torna-se também importante ressaltar que os programas de regularização fundiária, enquanto instrumento fundamental da política de desenvolvimento urbano, se constitue antes de tudo, ainda que tardiamente, em alternativas criadas pelo estado, não apenas para a definição de uma ordem urbanística que se deseja inclusiva, mas como condição sine qua non de combate aos processos cíclicos de informalidade urbana. Em síntese, os apontamentos realizados evidenciaram que a questão urbana no Brasil permaneceu por muito tempo abandonada a própria sorte, proporcionando o aumento vertiginoso de demandas nas mais diversas áreas, que inegavelmente se cristalizam em tipologias disformes e vulneráveis a todo tipo de riscos. Frente aos efeitos decorrentes desse processo, tem-se o despertar do Estado, que tem procurado agir por meio de políticas públicas, que até o momento não tem conseguido produzir resultados satisfatórios. Desse modo, a percepção das causas que conduzem e motivam o processo de crescimento das áreas urbanas é de extrema relevância para a busca de intervenções que tenham como meta a construção de cidades justas, inclusivas, sustentáveis e democráticas.

Neste contexto, a discussão a respeito da problemática da efetividade das políticas públicas, gestão urbana e qualidade de vida são essenciais para uma reflexão analítica do paradigma do Direito à Cidade.

\section{REFERÊNCIAS}

ACSELRAD, Henri. Discursos da Sustentabilidade Urbana. Revista Brasileira de Estudos Urbanos e Regionais, Campinas: no 01, maio/ 1999.

ALFONSIN, Jaques Távora. Do "diga que não estou" à relação entre pobreza e função social da terra no Brasil. In: FERNANDES, E.; ALFONSIN, B. Direito Urbanístico: Estudos Brasileiros e Internacionais. Belo Horizonte: Del Rey, 2006.

BALBIM, Renato. Avanços Recentes no Quadro Normativo Federal da Regularização Fundiária. 2010. Disponível em: http://www.ipea.gov.br/ppp/index.php/PPP/article/viewFile/176/189>. Acesso em: 04 Março 2011. 
BRAGA, Roberto. Qualidade de vida urbana e cidadania. Território \& Cidadania. Rio Claro, SP, ano II, no 2, jun-dez, 2002. Disponível em: <http://www.rc.unesp.br/igce/planejamento/territorioecidadania/Artigos/Braga\%203.htm> 09 jan. 2009.

BRASIL. Constituição (1988). Constituição da República Federativa do Brasil: promulgada em 5 de outubro de 1988. . São Paulo: Revista dos Tribunais, 2009.

$\overline{17.07 .2001 .}$

. Lei Federal nº 10.257 (2001). Estatuto da Cidade. DOU 11.07.2001, ret. DOU

Prevenção de riscos de deslizamentos em encostas: guia para elaboração de políticas municipais / Celso Santos Carvalho e Thiago Galvão (orgs). Brasília: Ministério das Cidades; Cities Alliance, 2006. 111 p.

. Resolução CONAMA № 369, de 28 de março de 2006.

CHAUÍ, Marilena. O que é ideologia. São Paulo: Brasiliense, 1984.

CAMPO, Pedro Abramo. A dinâmica imobiliária. Elementos para o entendimento da espacialidade urbana. In: Cadernos IPPUR/UFRJ, ano III, n. especial, dez. 1989. Rio de Janeiro: UFRJ, 1989. pp. 47-70.

CASTELLO, Lineu. A Percepção em Análises Ambientais. Percepção Ambiental - A Experiência Brasileira, São Carlos, Editora da UFSCAR, 1996.

DAVIS, MikeDavis. Planeta Favela.Sao Paulo, Boitempo, 2006.

DI PIETRO, Maria Sylvia Zanella. Bens públicos: domínio urbano: infra-estrutura. Belo Horizonte: Fórum, 2007, 360 p.

ESTATUTO DA CIDADE. Lei no 10.257, de 10 de julho de 2001, que estabelece diretrizes gerais da política urbana. Guia para implementação pelos municípios e cidadãos. Brasília: Câmara dos Deputados, Coordenação de Publicações, 2001.

FERNANDES, Edésio. Questões anteriores ao Direito Urbanístico. Belo Horizonte: PUC Minas Virtual, 2006.

Regularização de Assentamentos Informais: 0 grande desafio dos municípios, da sociedade e dos juristas brasileiros. In: ROLNIK, Raquel (org) Regularização Fundiária Plena: Referências Conceituais. Brasília: Ministério das Cidades,2007.

Regularização de Assentamentos Informais: o grande desafio dos municípios, da sociedade e dos juristas brasileiros. In: ROLNIK, Raquel et. al. (coord.). Regularização Fundiária de Assentamentos Informais Urbanos. Belo Horizonte: PUC Minas Virtual, 2006. 
FIGUEIREDO, Guilherme José Purvin. A propriedade no Direito Ambiental. Rio de Janeiro: Esplanada, 2004.

FIORILlO, Celso Antonio Pacheco. Curso de Direito Ambiental Brasileiro. 4ª ed. São Paulo: Saraiva, 2003.

GROSTEIN, M. D. Metrópole e Expansão Urbana: a Persistência de Processos "Insustentáveis". São Paulo em Perspectiva. Fundação SEADE. № 01, 2001.

GUIMARÃES, Solange T. de Lima. Nas Trilhas da Qualidade: algumas idéias, visões e conceitos sobre qualidade ambiental e de vida..., Revista GEOSUL, UFSC, Florianópolis, n.40, p. 7-26, jul./dez. 2005, Disponível em: <http://www.cultiva.org.br/pdf/qualidade_ambiental_e_da_vida.pdf> Acesso em: 15 jan. 2009.

IBGE (Instituto Brasileiro de Geografia e Estatística). Censo Demográfico de 2000. Disponível em: <http://www.ibge.gov.br> Acesso em: 20 fev. 2009.

LIRA, Ricardo Pereira. Elementos de Direito Urbanístico. Rio de Janeiro: Renovar, 1997.

LEFEBVRE, Henri. O Direito a Cidade. Sao Paulo: Centauro, 2008.

LÜDKE, Menga; ANDRÉ, Marli E. D. A. Pesquisa em educação: abordagem qualitativa. São Paulo: EPU, 1986, 99 p.

MANCUSO, Rodolfo de Camargo. Comentário ao Código de Proteção ao Consumidor. São Paulo: Saraiva, 1991, p.275.

MARICATO, Erminia T.M. Metropole da Periferia do Capitalismo: ilegalidade, desigualdade e violência. Sao Paulo: Hucitec,1996.

MARTINS, Maria Lucia Refinetti. Moradia e Mananciais: tensão e dialogo na metrópole. Sao Paulo: FAU-USP/FAPESP, 2006, 206p.

MAZETTO, Francisco de Assis Penteado. Qualidade de vida, qualidade ambiental e meio ambiente urbano: breve comparação de conceitos. Sociedade \& Natureza, Uberlândia, v. 14, n.24, p. 21-31, jun./dez. 2000.

MINISTÉRIO DAS CIDADES. Planos de Habitação de Interesse Social. PLHIS - Módulo 2 - Diagnóstico, Necessidades Habitacionais. Secretaria Nacional da Habitação, 2007.

MORAES, Lúcia; DAYRELL, Marcelo. Direito Humano à Moradia e Terra Urbana. Curitiba: INESC, 2008.

PIRES, Luis Manuel Fonseca. Loteamentos Urbanos: natureza jurídica. São Paulo: Quartier Latin, 2006, 160 p. 
PISSOL, Kátia Maria Santos de Andrade. A Dinâmica Urbana: Uma Leitura da Cidade e da Qualidade de Vida no Urbano. Caminhos de Geografia, Uberlândia - MG, v. 7, n. 17, p. 1-7, fev. 2006, ISSN: 1678-6343. Disponível em: $<$ <ttp://www.caminhosdegeografia.ig.ufu.br/viewarticle.php?id=25\&layout=abstract> Acesso em: 10 jan. 2009

RICHARDSON, P. G.. Piaget: teoria e práticas. São Paulo: Ibrasa, 1981.

ROLNIK, Raquel. Planejamento Urbano nos Anos 90: Novas Perspectivas para Velhos Temas. RIBIERO; QUEIROZ, Luiz César; SANTOS JUNIOR, Orlando Alves (Orgs.). Globalização, Fragmentação e Reforma Urbana. Rio de Janeiro: Civilização Brasileira: 1997, p. 351-360.

ROSSET, Franciele. Procedimentos metodológicos para estimativa do índice de áreas verdes públicas. Estudo de caso: Erichim, RS. 2005. 60 p. Dissertação (Mestrado) Universidade de São Carlos, São Carlos, 2005. Disponível em: <http://www.bdtd.ufscar.br/tde_busca/arquivo.php?codArquivo=631>. Acesso em: 7 jan. 2009.

SAULE JUNIOR, Nelson. O Direito à moradia como responsabilidade do Estado Brasileiro. In. Caderno de Pesquisa do CEBRAP - Centro Brasileiro de Análises e Planejamento, n. 7, maio 1997.

Estatuto da Cidade: Instrumento de reforma Urbana. [on-line] Disponível em<http://www.estatutodacidade.org.br/estatuto/artigos.shtml>. Acesso em 20 de abril de 2005.

SAULE JÚNIOR, Nelson (org.). Direito Urbanístico: Vias jurídicas das políticas urbanas. Porto Alegre: 2007.

SCHEID, Cintra Maria. A Regularização Fundiária dos Assentamentos Urbanos Informais como Garantia do Mínimo Existencial no Direito a Moradia, 2008. Dissertação de Mestrado. Programa de Pós-Graduação em Direito - Área de Concentração em Direitos Sociais e Políticas Públicas - Universidade de Santa Cruz, 2008.

SILVA, José Afonso da. A dignidade da pessoa humana como valor supremo da democracia. In: Revista de Direito Administrativo, Rio de Janeiro: Renovar, n. 212, abril/junho 1998.

SMOLKA, Martin O. O capital incorporador e seus movimentos de valorização. In: Cadernos IPPUR/UFRJ, ano II, n.1, jan/abr. 1987. Rio de Janeiro: UFRJ, 1987. pp. 41-78.

SOUSA JÚNIOR, José Geraldo. Ensino jurídico: pesquisa e interdisciplinaridade. In: OAB ensino jurídico: Novas diretrizes curriculares. Brasília: 6 Conselho Federal da OAB, 1996 
SUNDFELD, Carlos Ari, O Estatuto da Cidade e suas Diretrizes Gerais. In: Estatuto da Cidade - Comentários a Lei Federal 10.257/01, São Paulo, Ed. Malheiros, 2002 - $1^{\underline{a}}$ Edição, p. 59/60.

VILLAÇA, F. Espaço intra-urbano no Brasil. São Paulo: Nobel, 1998.

VILANI, Rodrigo Machado. O princípio de justiça social e ambiental e a eficácia do plano diretor participativo. 2002. $229 \mathrm{f}$. Tese (Doutorado em Meio Ambiente e Desenvolvimento) - Universidade Federal do Paraná, 2006. 